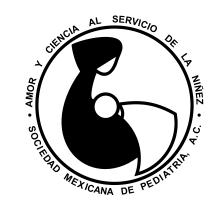

\title{
Hipermagnesemia neonatal secundaria a intoxicación por laxante oral con sales de magnesio
}

\author{
Cristina Menéndez-Hernando, ${ }^{1, *}$ Aida de La Huerga-López, ${ }^{2}$ Raquel Martín-Molina, ${ }^{2}$ \\ Mercedes Fariñas-Salto, ${ }^{2}$ Rocío Chacón-Aguilar ${ }^{2}$ \\ ${ }^{1}$ Clínica Universidad de Navarra; ${ }^{2}$ Hospital Universitario Infanta Leonor, Madrid, España.
}

Palabras clave: Hipermagnesemia, recién nacido, magnesio.

\section{INTRODUCCIÓN}

El magnesio es el segundo catión intracelular más abundante en el organismo. Es cofactor en más de 300 reacciones enzimáticas que afectan el metabolismo energético, regulan la contractilidad, el tono muscular, la conducción de impulsos nerviosos, la contractilidad cardiaca y el tono vasomotor. Es indispensable en la síntesis de proteínas y ADN. El riñón es el principal órgano excretor que mantiene los niveles normales

\footnotetext{
* Correspondencia: $\mathrm{CMH}$, cristinamenendezh@gmail.com Conflicto de intereses: Las autoras declaran que no tienen. Citar como: Menéndez-Hernando C, De La Huerga-López A, Martín-Molina R, Fariñas-Salto M, Chacón-Aguilar R. Hipermagnesemia neonatal secundaria a intoxicación por laxante oral con sales de magnesio. Rev Mex Pediatr. 2019; 86(5):194-196. [Neonatal hypermagnesemia due to oral laxative intoxication with magnesium salts]
}

\begin{abstract}
RESUMEN
Introducción: La hipermagnesemia neonatal (más de 3 mg/ $\mathrm{dL}$ ) es poco frecuente y generalmente asintomática. Suele manifestarse como hipotonía, debilidad muscular, hipotensión, pausas y arritmias. Caso clínico: Se presenta el caso de recién nacida (RN) prematura con intoxicación neonatal por laxante oral con sales de magnesio, debido a error de dosificación. La RN mostró distensión abdominal severa, intolerancia oral y decaimiento. El tratamiento fue líquidos intravenosos, aporte de calcio y diuréticos. Al parecer este el primer caso de intoxicación por laxante oral con sales de magnesio en neonatos.
\end{abstract}


casos descritos de intoxicación neonatal por sales de magnesio orales (Eupeptina ${ }^{\circledR}$, en España).

\section{PRESENTACIÓN DEL CASO}

$\mathrm{RN}$ prematura de 25 semanas de edad gestacional con buena evolución clínica, relativamente se mantuvo sin complicaciones mayores hasta las 37 semanas de edad postmenstrual, presentó sepsis neonatal secundaria a corioamnionitis, además de ductus arterioso que fue cerrado farmacológicamente. Cursó también con pausas de apnea resueltas sin tratamiento desde la semana 32, y anemia de la prematuridad.

Permaneció ingresada en neonatología por dificultades en la alimentación y escasa ganancia ponderal; a las 35 semanas se detectó estreñimiento por lo que precisó estimulación rectal para lograr evacuaciones. Para el tratamiento de estreñimiento se prescribió Eupeptina ${ }^{\circledR}$ una cucharadita en todos los biberones (32 mg). En las siguientes 24 horas inició con pausas de apnea centrales, hipoactividad progresiva, decaimiento, mala tolerancia oral con marcada distensión abdominal, pero sin cambios de coloración, ni dolor a la palpación.

Al revisar la prescripción se observó que hubo un error en la dosis del laxante. La dosis habitual es una cucharadita cada 12 horas (dosis máxima 8 g/día), es decir, se administró cuatro veces más. Por esta razón, se suspenden las sales de magnesio y se deja en ayuno. Se inician líquidos parenterales y antibióticos. En los exámenes de laboratorio el hemograma fue normal, existe equilibrio ácido-base, calcio total $9.6 \mathrm{mg} / \mathrm{dL}$, calcio iónico $1.3 \mathrm{mEq} / \mathrm{l}$, fósforo $7.1 \mathrm{mg} / \mathrm{dL}$, magnesio 4.4 $\mathrm{mg} / \mathrm{dL}$, fosfatasa alcalina $650 \mathrm{mg} / \mathrm{dL}$, PCR $3.5 \mathrm{mg} / \mathrm{dL}$.

Electrocardiograma ritmo sinusal, sin arritmias. Radiografía de abdomen: asas muy distendidas con gas distal sin niveles hidroaéreos, neumatosis o signos de aire ectópico.

Ante la sospecha clínica de hipermagnesemia por íleo paralítico y pausas de apnea secundarias, se agregó furosemida ( $1 \mathrm{mg} / \mathrm{kg} /$ día) y calcio (4 mEq/kg/día). En las siguientes 24 horas hubo mejoría clínica progresiva con estabilidad respiratoria, normalización de la exploración abdominal, de la tolerancia oral y se muestra más activa. En el examen de control a las 24 horas, se observó normalización del magnesio $(2.4 \mathrm{mg} / \mathrm{dL})$.

\section{DISCUSIÓN}

La intoxicación por magnesio es una complicación relativamente frecuente, pero poco conocida en $\mathrm{RN}$. Los datos clínicos son hipotonía, debilidad muscular, alteraciones en el comportamiento, hipotensión, pausas respiratorias y arritmias. ${ }^{4}$ Aunque el íleo paralítico secundario a hipermagnesemia ha sido comunicado en adultos no es tan frecuente en RN; en los reportes previos, se relaciona con retraso en la eliminación de meconio y enlentecimiento en el tránsito. Hay un caso publicado de perforación intestinal. ${ }^{4}$ Los casos descritos suelen ser secundarios a fármacos de administración vía oral (enemas de magnesio, antiácidos) y cuyo uso ya no es una práctica en RN neonatal.

Se cree que el magnesio disminuye la peristalsis intestinal al afectar directamente las células del músculo liso o al deprimir la excitabilidad de fibras nerviosas musculares. El efecto en el sistema nervioso central incluye alteraciones del sueño, depresión respiratoria y apneas. En pacientes adultos parece que las manifestaciones se relacionan con las concentraciones séricas de magnesio; en RN esto no es tan claro. Se ha descrito que los síntomas inician con niveles mayores

\section{Tabla 1: Valores de magnesio normales en la primera semana de vida. ${ }^{1}$}

Recién nacido hijo de madre que no ha recibido tratamiento con magnesio
Recién nacido hijo de madre con tratamiento con magnesio

$\begin{array}{lcc}\text { Sangre de cordón } & 0.52-0.99 \mathrm{mmol} / \mathrm{L} & 0.5-2.08 \mathrm{mmol} / \mathrm{L} \\ & 1.24-2.3 \mathrm{mg} / \mathrm{dL} & 1.2-4.99 \mathrm{mg} / \mathrm{dL} \\ \text { Primera semana de vida } & 0.55-1.26 \mathrm{mmol} / \mathrm{L} & 0.61-2.27 \mathrm{mmol} / \mathrm{L} \\ & 1.1-2.5 \mathrm{mg} / \mathrm{dL} & 1.4-5.4 \mathrm{mg} / \mathrm{dL}\end{array}$

${ }^{1}$ Adaptado de: Rigo J, Pieltain C, Christmann V, Bonsante F, Moltu SJ, lacobelli S et al. Serum magnesium levels in preterm infants are higher than adult levels: a systematic literature review and meta-analysis. Nutrients. 2017; 9(10): pii: E1125. 
de $3 \mathrm{mg} / \mathrm{dL}$ y que los síntomas graves son con niveles superiores a $6 \mathrm{mg} / \mathrm{dL}{ }^{4}$

La Eupeptina ${ }^{\circledR}$ es un laxante osmótico cuyo contenido principal son sales de magnesio ( $31 \mathrm{~g}$ de sales cada $100 \mathrm{~g}$ del producto) y se usa fundamentalmente en atención primaria para el tratamiento de constipación en los primeros meses de vida. Actúa aumentando la presión osmótica del interior del intestino delgado, provoca la liberación de agua hacia la luz intestinal e induce una evacuación rápida. Sin embargo, la posología de este medicamento es muy inexacta, ya que la presentación es en polvo, y se suele indicar la administración de "una cucharadita de café" (aproximadamente $4 \mathrm{~g}$ ) cada 12-24 horas, de ahí que cuando el tratamiento es ambulatorio, es importante repasar la posología para evitar errores de dosificación en el domicilio.

Nuestra paciente recibió durante 48 horas cuatro veces más la dosis máxima debido a un error de prescripción y presentó un cuadro con alteraciones digestivas, porque el magnesio actuó de manera directa relajando las fibras musculares del intestino. En contraste, en la literatura sobre casos de $\mathrm{RN}$ se describe como un cuadro sistémico, probablemente debido a la administración por vía intravenosa (para corrección de hipomagnesemia o por errores en nutrición parenteral), o por paso transplacentario (cuando el magnesio es administrado a la madre). En los casos revisados no se describe algún paciente con intoxicación por magnesio que presentara manifestaciones clínicas digestivas graves como el presentado en este caso clínico.
El tratamiento de la hipermagnesemia depende de la gravedad de los síntomas. Siempre se deben suspender los suplementos de magnesio y monitorizar calcio, fosfato, magnesio y equilibrio electrolítico. En caso de distensión abdominal severa o restos gástricos se recomienda dejar en ayuno, con sonda abierta hasta que mejore la distensión. Cuando los síntomas son leves el soporte es con líquidos parenterales con gluconato cálcico (ya que antagoniza el efecto del magnesio en el sistema nervioso central) y forzar diuresis. Si las manifestaciones son graves se puede requerir ventilación mecánica y soporte inotrópico; en pacientes que continúan inestables se recomienda exanguinotransfusión o diálisis.

\section{REFERENCIAS}

1. Rigo J, Pieltain C, Christmann V, Bonsante F, Moltu SJ, lacobelli $S$ et al. Serum magnesium levels in preterm infants are higher than adult levels: a systematic literature review and meta-analysis. Nutrients. 2017; 9(10): pii: E1125.

2. Lipsitz PJ, English IC. Hypermagnesemia in the newborn infant. Pediatrics. 1967; 40(5): 856-862.

3. Greenberg MB, Penn AA, Thomas LJ, El-Sayed YY, Caughey AB, Lyell DJ. Neonatal medical admission in a term and late-preterm cohort exposed to magnesium sulfate. Am J Obstet Gynecol. 2011; 204(6): 515.e1-7.

4. Narchi H. Delayed intestinal transit and arrhythmias due to iatrogenic neonatal hypermagnesemia. Int Pediatr. 2002; 17(3): 154-155.

5. Sullivan JE, Berman BW. The pediatric forum: hypermagnesemia with lethargy and hypotonia due to administration of magnesium hydroxide to a 4-week-old infant. Arch Pediatr Adolesc Med. 2000; 154(12): 1272-1724. 